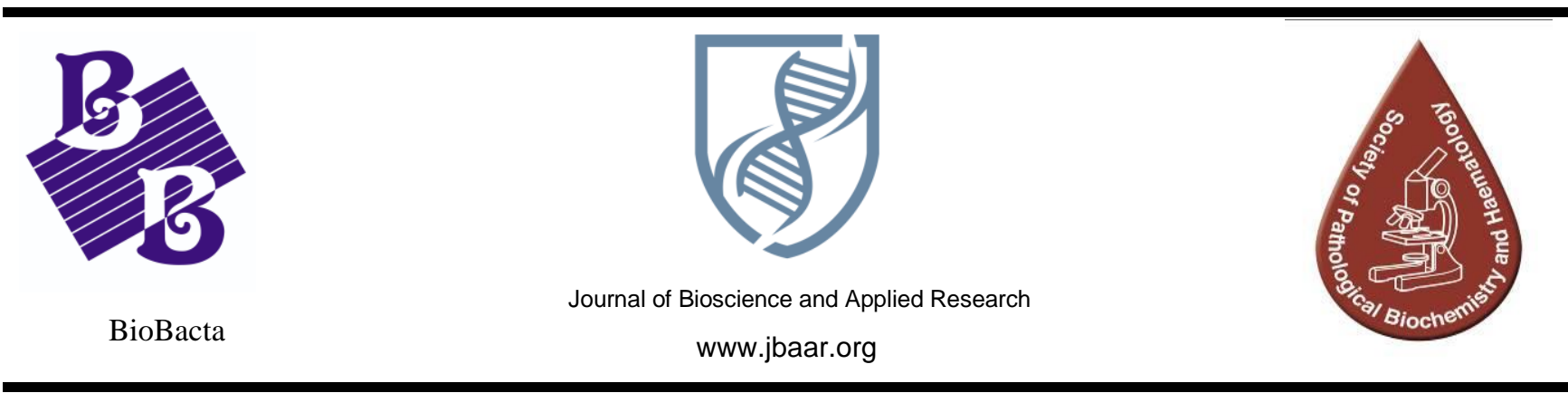

\title{
Effect of Moringa oleifera leaves extract against electromagnetic field impairments on hemoglobin and testes of rat
}

\author{
Aida A. Salama *; Aziza A. Elsaeid * Shoman, H.M.** and Ola Mohamed Awad * \\ * Biophysics Department, Faculty of Science, Al-Azhar University, Cairo, Egypt \\ ** Zoology Department, Faculty of Science, Al-Azhar University, Cairo, Egypt \\ Received: June 7, 2020. Accepted: July 28, 2020. Published: August 11, 2020
}

DOI: 10.21608/jbaar.2020.107799

\begin{abstract}
:
The present study has revealed the effect of Moringa oleifera leaves extract against electromagnetic field induced impairments. Forty-two adult white Albino male rats, weighting 150-180 g were involved in this study and divided into six equal groups. The first group was the control while the second group was daily supplemented with $200 \mathrm{mg} / \mathrm{kg}$ Moringa oleifera leaves extract orally for six days. The third group was exposed to an electromagnetic field of $1.5 \mathrm{mT}, 50 \mathrm{~Hz}$ for 9 hours. The other three groups were exposed to an electromagnetic field of $1.5 \mathrm{mT}, 50 \mathrm{~Hz}$ for 9 hours, and received the Moringa oleifera leaves extract in different supplemented ways. Blood samples were collected for the absorption spectrum of hemoglobin molecules analysis and serum total testosterone was studied. Samples of testes were taken for histopathological observations. The results showed that exposure of the animals to the electromagnetic field resulted in changing the absorption spectrum of hemoglobin, a highly significant reduction in testosterone level, and degenerative changes in testes. All these induced changes were decreased in groups treated by Moringa oleifera leaves extract in all ways. So through this study, one can conclude that damages induced by exposure to the electromagnetic field can be decreased by Moringa oleifera leaves extract.
\end{abstract}

Keywords: Moringa oleifera, electromagnetic field, hemoglobin molecules, testosterone, testes of rat

\section{Introduction:}

Technology allowed the expansion of many different apparatuses that emitting electromagnetic fields (EMF) such as mobile phones, satellite signals, television sets, microwaves, and computers. So we are exposed to EMF daily (Abd El-Hady and ElTahawy, 2015). EMF might adversely effect the electrical properties of membrane proteins, so there are reports that EMF could be dangerous (Yildiz-
Gulay et al. 2017). Hassan and Abdelkawi, (2010) stated animals exposed to static magnetic fields have showed changes in the absorption spectrum of hemoglobin ( $\mathrm{Hb})$ molecules. Azab et al. (2018) reported that exposure to EMF resulted in a decrement in serum levels of testosterone, sperm motility, count, and induced sperm abnormalities. The testis in which the male reproductive gonad is very sensitive to many factors such as inflammation, 
hyperthermia, and radiation (Bahaodini et al. 2015). Elbaz and Ghonimi, (2015) studied the effects of exposure to a $0.1 \mathrm{mT}$ magnetic field on mature male albino rats. Their results showed pathological injuries in testis. Adah et al. (2018) concluded that EMF induced changes in the male reproductive system. These changes include spermatozoa decreased motility, morphometric abnormalities, increased peroxidation due to oxidative stress and histopathological changes in the testes.

Moringa oleifera is the most cultivated in tropical and subtropical countries. The leaves of these plants are highly valued nutritious, they rich with vitamins $\mathrm{A}, \mathrm{B}, \mathrm{C}$ and $\mathrm{E}, \beta$-carotene, nicotinic acid, folic acid, protein, various phenolic compounds, amino acids, and minerals (Khalafalla et al. 2010). Bin-Meferij and El-kott, (2015) showed that polyphenolic-rich Moringa oleifera leaves extract (MOLE) able to protecting rat testis against EMF induced impairments. Also, Syarifuddin et al. (2017) reported that MOLE supplementation increased testosterone and motility of sperm. The aim of this study is to investigate the effect of MOLE against damage induced by EMF in rats.

\section{Materials and Methods:}

\section{Experimental animals:}

In this study (42) white Albino male rats, weighing150-180 $\mathrm{g}$ were involved. The rats were divided into six equal groups; each group containing 7 rats.
1- Group (A): was the control group received an only standard diet.

2- Group (M): was supplemented daily and for six days with $200 \mathrm{mg} / \mathrm{kg}$ MOLE orally.

3- Group (B): was exposed to EMF of $1.5 \mathrm{mT}, 50 \mathrm{~Hz}$ for 9 hours.

4- Group (N): protection model, was supplemented daily, and for six days with $200 \mathrm{mg} / \mathrm{kg}$ of MOLE then exposed to EMF of $1.5 \mathrm{mT}$ for 9 hours.

5- Group (T): treatment model, was exposed to EMF of $1.5 \mathrm{mT}, 50 \mathrm{~Hz}$ for 9 hours then supplemented daily and for six days with $200 \mathrm{mg} / \mathrm{kg}$ of MOLE.

6- Group (C): contain both protection and treatment models, was supplemented daily, and for three days with $200 \mathrm{mg} / \mathrm{kg}$ of MOLE then exposed to EMF of $1.5 \mathrm{mT}, 50 \mathrm{~Hz}$ for 9 hours then supplemented daily and for three days with $200 \mathrm{mg} / \mathrm{kg}$ MOLE.

\section{Electromagnetic field exposure device:}

The exposure device consists of a coil placed on a wooden rack which with 320 turns of $2 \mathrm{~mm}$ copper wire wounded around a copper cylinder of $2 \mathrm{~mm}$ thick, $50 \mathrm{~cm}$ in diameter and $60 \mathrm{~cm}$ in length. The coil ends were connected to a variac that was fed from the mains $(220 \mathrm{Vpp}$ and $50 \mathrm{~Hz})$ to produce the electromagnetic field as shown in fig. (1). The magnetic field of $1.5 \mathrm{mT}$ (in the area where the animals housed) was adjusted by Gauss/Tesla Meter, Model CYHT208 No: BH13049 - Chenyang.

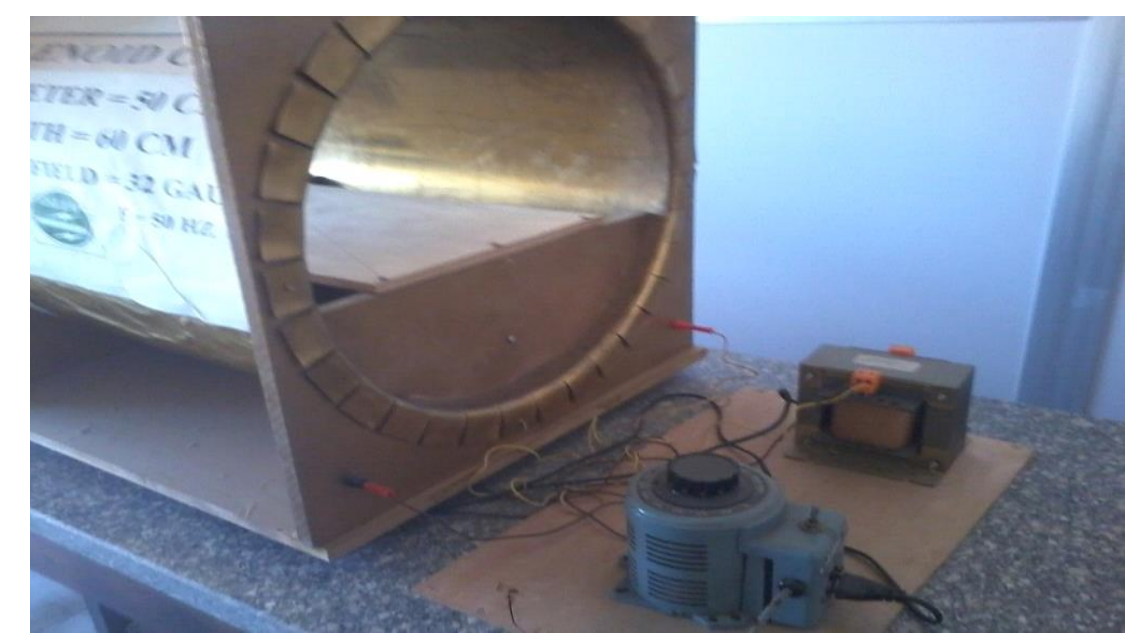

Fig. (1): The exposure device 


\section{Ethanolic Moringa oleifera leaves extract:}

Moringa oleifera leaves ethanolic extract was prepared according to the technique mentioned by Okechukwu et al. (2013). Firstly, the leaves were dried at $29-35^{\circ} \mathrm{C}$ for three weeks then grinded. The grinded leaves were extracted (using a soxhlet extractor unit) by absolute ethanol and left for 48 hours. The extraction was evaporated to dryness using a rotary evaporator at $40-45^{\circ} \mathrm{C}$. The extract was diluted using a polysaccharide to $1000 \mathrm{ml}$ as a carrier and kept in the fridge. Finally, the diluted extraction was lightened with diluted by distilled water to equilibrate $1 \mathrm{~kg}$ of leaves powder/Liter.

\section{Absorption spectrum analysis:}

The rats under studying were anaesthetized with diethyl ether. Blood samples were taken from them by draining the blood from their eyes into tubes containing heparin, using capillary tubes. The tubes sealed and gently checked ready for performing measurements. Hemoglobin was extracted by the method of Trivelli et al. (1971) with modification. After hemoglobin extraction, its concentration was adjusted by appropriate dilution with deionized water at room temperature $25 \pm 1^{\circ} \mathrm{C}$ on the base of the heme absorption band at $576 \mathrm{~nm}$ where the absorbance of $\mathrm{Hb}$ at $576 \mathrm{~nm}$ equals 0.5 . The absorption spectrum of hemoglobin was measured in the wavelength range between $200-800 \mathrm{~nm}$ at room temperature $\left(25 \pm 1^{\circ} \mathrm{C}\right)$ using an automatic recording double beam UV -Vis spectrophotometer type Perkin Elemer precisely (Lambada 45) - Germany.

\section{Total testosterone measurement:}

Blood samples were taken from Albino male rats by draining the blood from their eyes into tubes without anticoagulants; using capillary tubes and allowed to clot. The clotted blood samples were centrifuged at $2000 \mathrm{rpm}$ for $15 \mathrm{~min}$ to obtain the serum. The serum was stored at $-25^{\circ} \mathrm{C}$ until analysis.

\section{Histological procedure:}

The rats were anaesthetized with diethyl ether and tests of both control and experimental rats were removed and prepared according to the method described by Drury et al. (1973). The method involves the fixation of the specimens in Boun's fluid and formalin $10 \%$ for 48 hours then dehydrated in a series of descending grades ethyl alcohol 70, 80, 90, and $100 \%$, after that cleared by using cedar wood oil as a clearing agent. The cleared specimens were embedded in paraffin wax at $\left(56-58^{\circ} \mathrm{C}\right)$, then sectioned at $5 \mu$ thickness by using a microtome. The sections were then stained with haematoxylin and eosin for microscopic examination.

\section{Statistical Analysis:}

Data were statistically analyzed by ANOVA test (SPSS version17).

\section{Results:}

\section{Absorption spectrum of hemoglobin:}

Figures (2\&3and 4) shows the absorption spectrum of $\mathrm{Hb}$ extracted for control and different experimental groups. Table (1) indicates the absorbance values for all groups and the ratio $\mathrm{A}_{576} / \mathrm{A}_{541}$. The absorption spectrum of $\mathrm{Hb}$ - control group shows the different bands in wave length range of $230-680 \mathrm{~nm}$. The bands were named as follow: $270 \mathrm{~nm}$ referred to a globin band, peak at $345 \mathrm{~nm}$ is a globin heme interaction band and referred to the noncovalent bond between globin's histidine and heme iron, peak at $419 \mathrm{~nm}$ is a soret band, peak at $540 \mathrm{~nm}$ is the Nitrogen-iron band and peak at $576 \mathrm{~nm}$ is the heme-heme interaction band. The difference between absorbance values for all bands between group (A) and $(\mathrm{M})$ is very small. Great differences were detected in all $\mathrm{Hb}$-absorption spectrum bands for EMF exposed group (B) and there is an increase in $\mathrm{A}_{576} / \mathrm{A}_{541}$ ratio (its value is accompanied with the appearance of a new band at wavelength $630 \mathrm{~nm}$ ). The difference decreased with using MOLE in all used ways. 


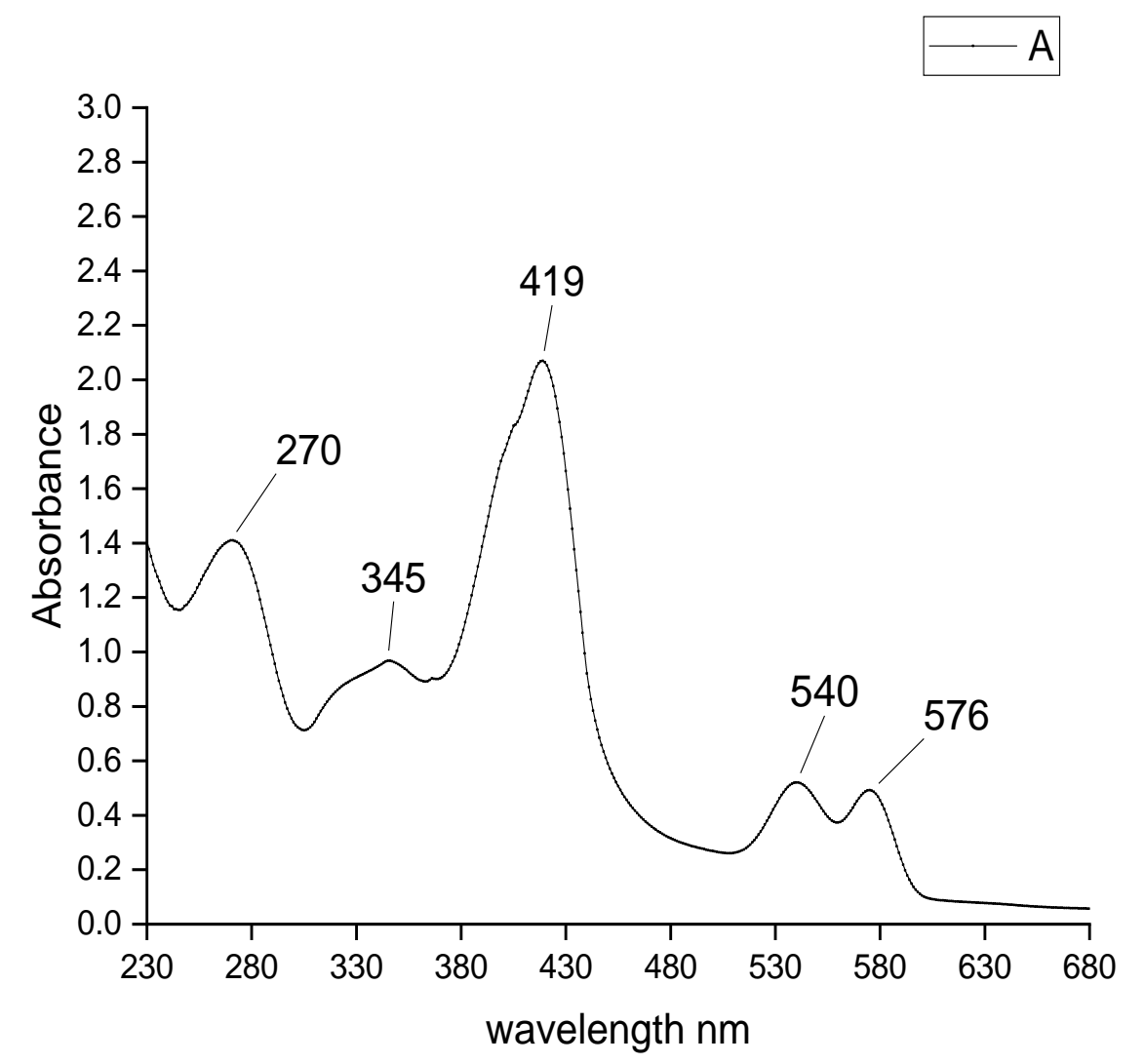

Fig. (2) Absorption spectrum of normal hemoglobin for control rat group (A) showing a characteristic bands

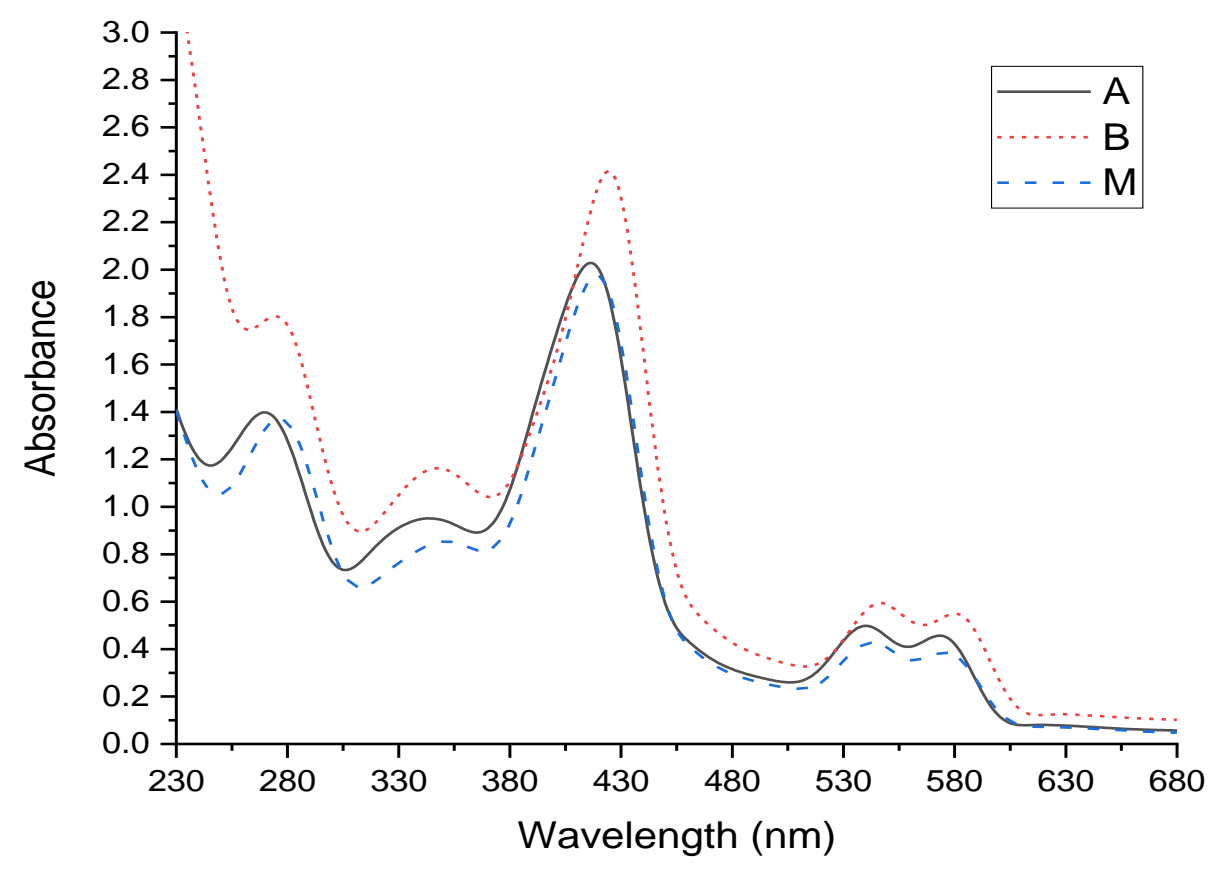

Fig.(3) Absorption spectrum of hemoglobin of rats which exposed to EMF of $1.5 \mathrm{mT}$ for 9 hours group (B) in comparison with group (M) and control one (A). 


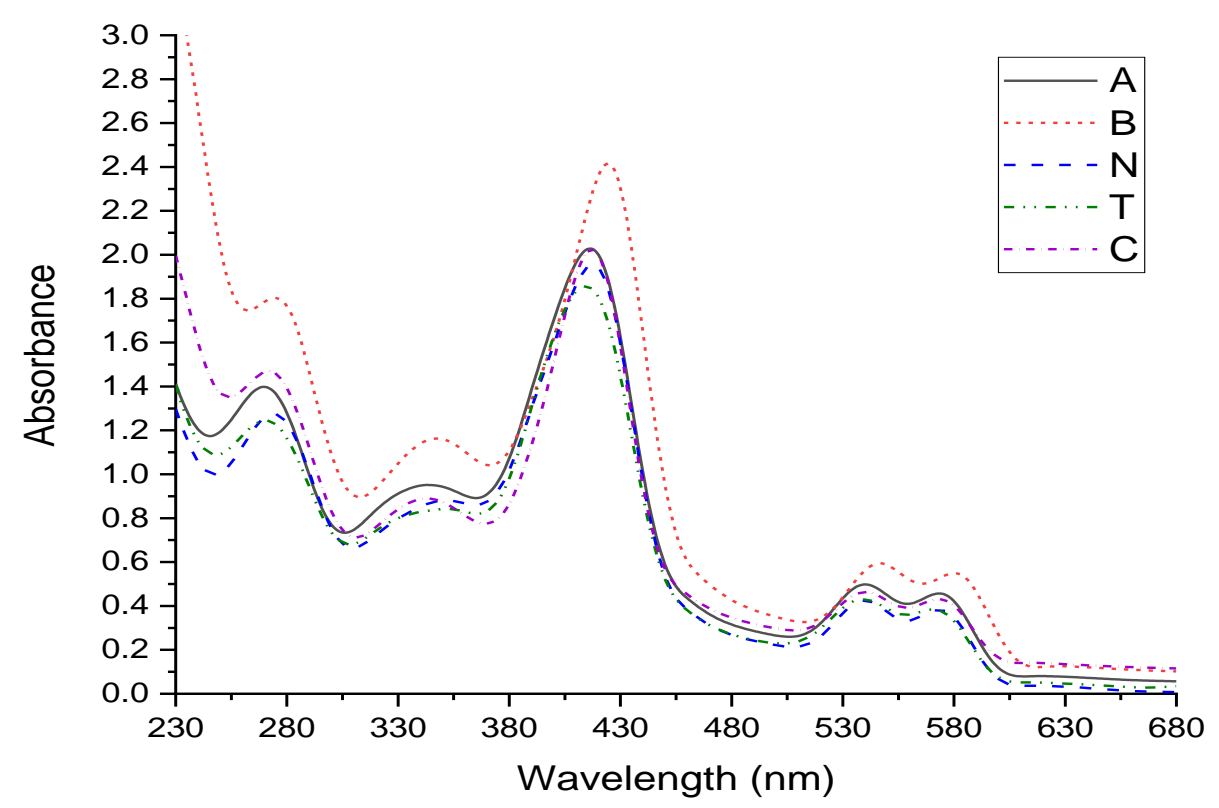

Fig. (4) Absorption spectrum of hemoglobin of rats which exposed to EMF of $1.5 \mathrm{mT}$ for 9 hours and treated with Moringa in different ways (N\&T and C) in comparison with a group(B) and the control one (A).

Table (1): Absorption values of hemoglobin for experimental groups compared to the control one.

\begin{tabular}{|c|c|c|c|c|c|c|}
\hline Group & $\begin{array}{c}\text { Globin } \\
\text { Band } \\
270\end{array}$ & $\begin{array}{c}\text { Globin-heme } \\
\text { interaction } \\
345\end{array}$ & $\begin{array}{c}\text { Soret band } \\
419\end{array}$ & $\begin{array}{c}\text { Nitrogen- } \\
\text { iron band } \\
540\end{array}$ & $\begin{array}{c}\text { Heme-heme } \\
\text { interaction } \\
576\end{array}$ & $\begin{array}{c}\text { Ratio } \\
\mathbf{A}_{576} / \mathbf{A}_{540}\end{array}$ \\
\hline A & 1.4097 & .968 & 2.069 & .534 & .498 & 0.933 \\
\hline B & 1.752 & 1.158 & 2.357 & .546 & .524 & 0.961 \\
\hline $\mathbf{M}$ & 1.330 & .854 & 2.018 & .507 & .475 & 0.937 \\
\hline $\mathbf{N}$ & 1.265 & .889 & 2.008 & .515 & .484 & 0.941 \\
\hline $\mathbf{T}$ & 1.253 & .851 & 1.866 & .523 & .472 & 0.902 \\
\hline $\mathrm{C}$ & 1.480 & .898 & 2.090 & .503 & .481 & 0.956 \\
\hline
\end{tabular}




\section{Total testosterone measurement:}

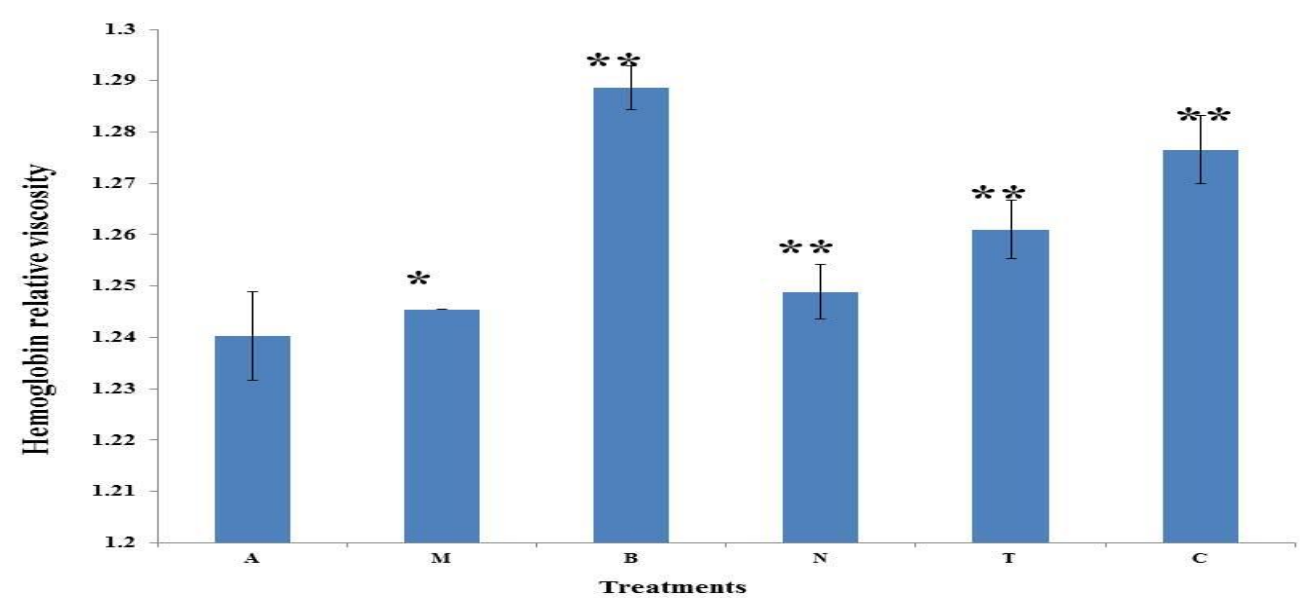

Fig.(5):Histogram of serum testosterone \pm SD for control and different experimental groups.*:high significant increase $(\mathrm{P} \leq 0.001) * *$ :High significant decrease $(\mathrm{P} \leq 0.001)$

Fig. (5): Summarizes the effects of $1.5 \mathrm{mT}$ EMF exposure on male rats testosterone and treatment with MOLE before $(\mathrm{N})$, after and before, and after exposure to EMF. The results showed a high significant increase in the serum levels of testosterone $(\mathrm{P} \leq 0.001)$ for $(\mathrm{M})$ group. On the other hand, high significant decrease on the serum levels of testosterone was observed $(\mathrm{P} \leq 0$.001) in EMF exposed group (B). The other three groups which take MOLE showed an increment in serum levels of testosterone in comparison with the exposed group, however, it still showed high significant decreases when compared with the control one.

\section{Histopathological observations:}
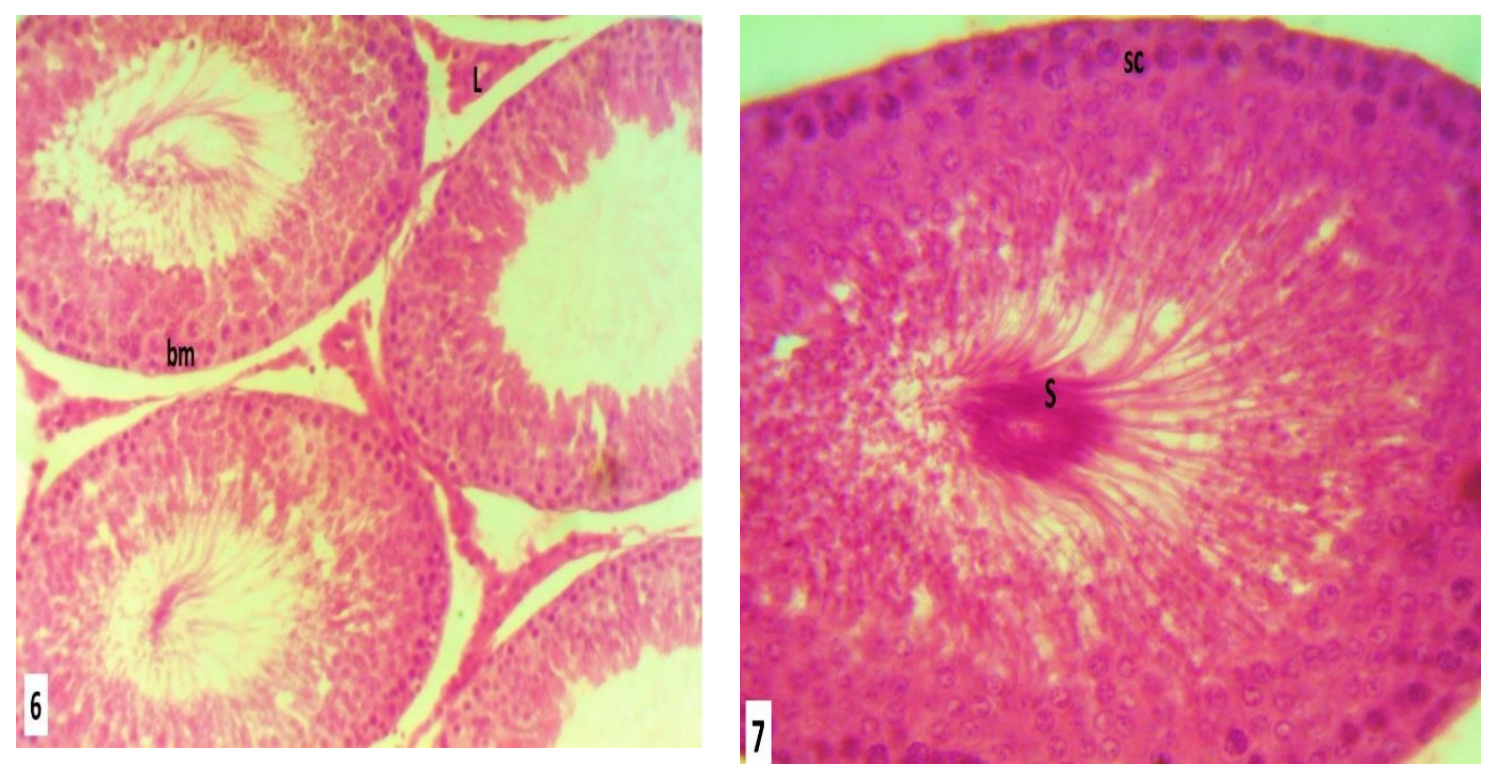

Figs. (6 and7) micrographs of transverse section of testis of groups (A) and (M) respectively showing normal seminiferous tubule. The seminiferous tubule has well-developed basement membrane (bm), numerous sertoli cell (sc) and sperms (s) in the lumens. Normal interstitial tissue in between the tubules which containing Leydig cells (L) 


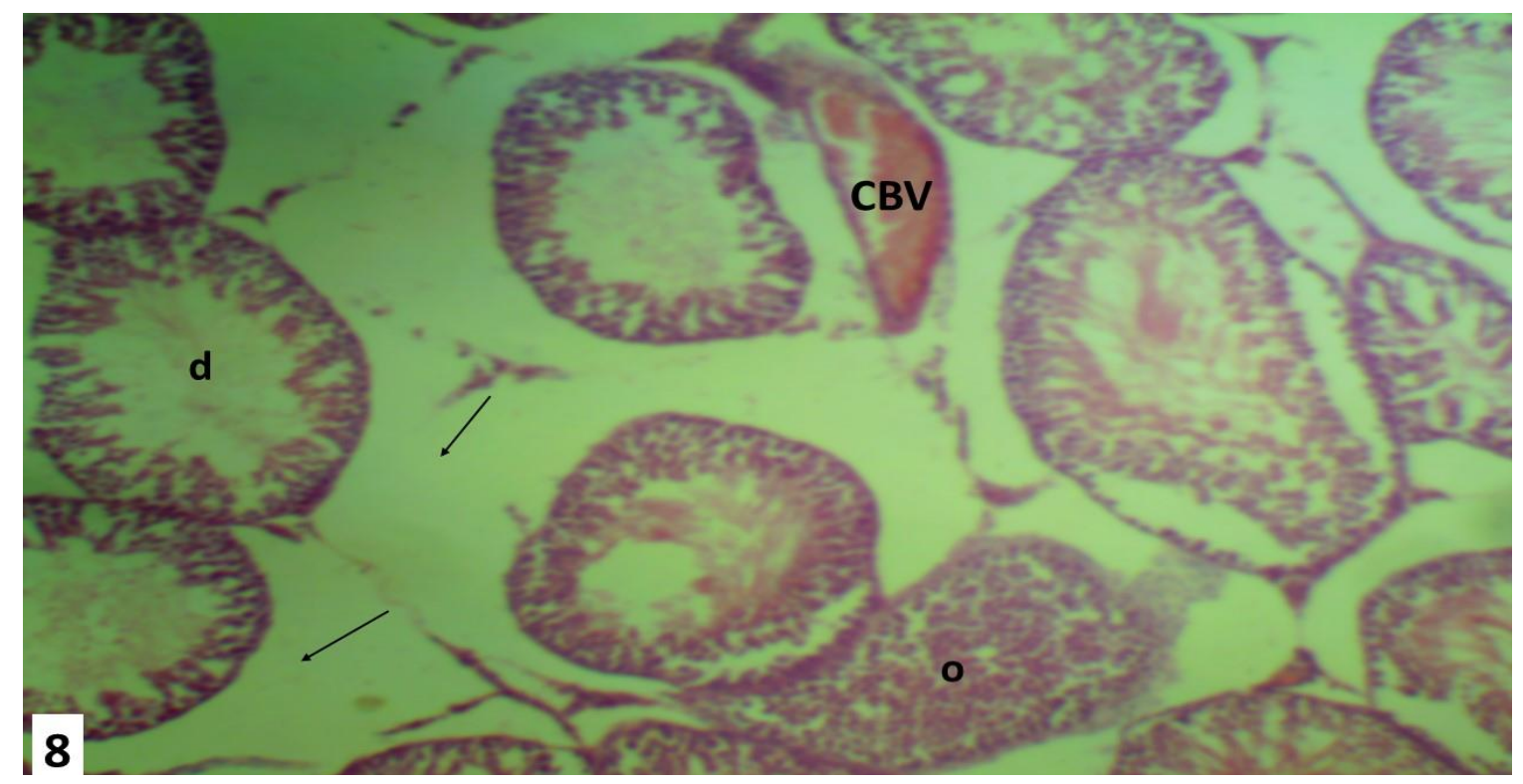

Fig.(8) Micrograph of transverse section of testis of group (B) showing disorganization (o) degeneration (d), decreased diameters and atrophy in some seminiferous tubules ,decreased interestial tissue, widening of interstitial spaces (arrows), highly reduced sperms in the lumen of the seminiferous tubules and reduction in Leydig cells $\mathbf{H} \& \mathbf{E}$, X 100).
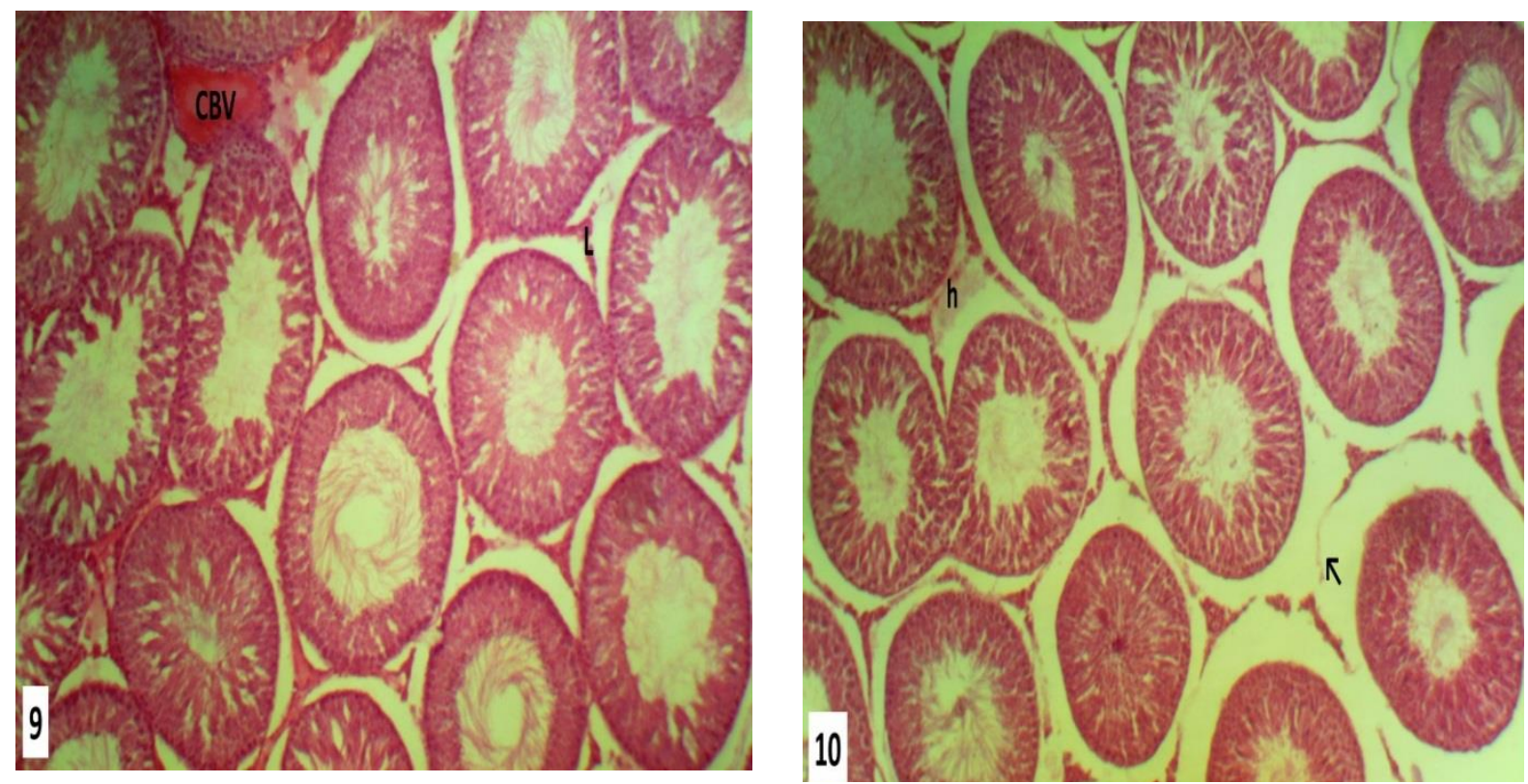


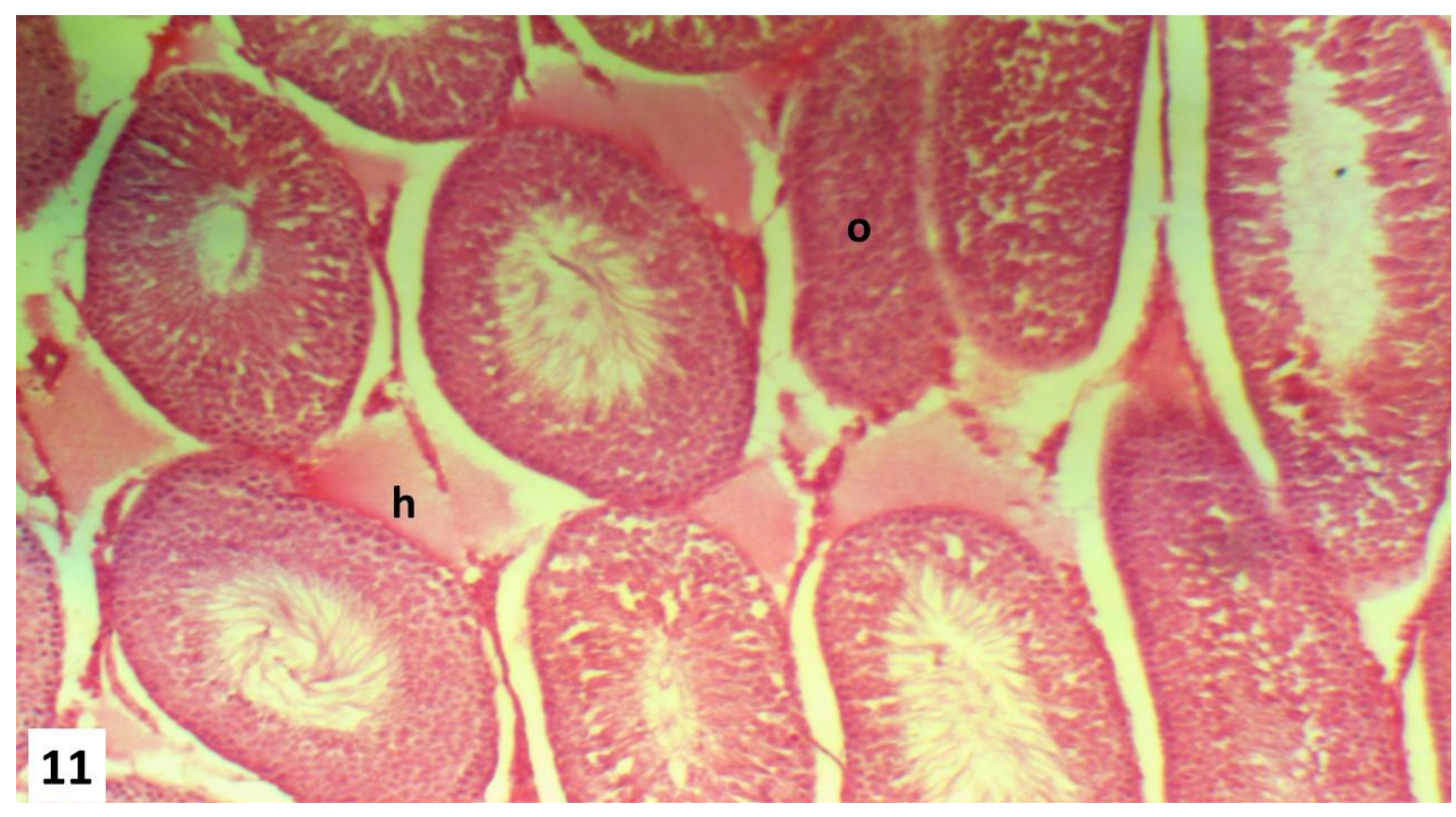

Figs. (9,10 and 11) Micrographs of a transverse section of testis of groups N, Tand C respectively showing enhancement in the seminiferous tubules with the reappearance of Leydig cells (L) and sperms. However, some changes still found such as congested blood vessel(CBV), widening of interstitial spaces (arrows), disorganization (o), hemorrhage and atrophy in some seminiferous tubules (H\&E, X 100).

Examination of hematoxylin and eosin-stained sections of control testes (Group A) and group (M) showed normal histological structure of testis tissue which showed normal seminiferous tubules, Leydig cells which were randomly distributed in between the seminiferous tubules, basement membranes and normal mature sperms which collected in the middle of the seminiferous tubules (Figs. 6 and 7). Sertoli cells which are large epithelial cells and have a large nucleolus showed also normal appearance. On the other hand, the sections of testis which exposed to EMF showed a degenerative changes represented in disorganization, degeneration and atrophy in some seminiferous tubules tissue, highly reduced number of Leydig cells, congested blood vessel (CBV) and dilation in interstitial spaces. Reduction in spermatogenic layers and cells and reduction in the number of mature sperms were also noticed (Fig.8). The examination of the testicular tissues of rats treated with Moringa oleifera leaves extract in all treatment designs showed somewhat normal appearance. However, some changes still found such as congested blood vessels, widening of interstitial spaces, disorganization, hemorrhage, and atrophy in some seminiferous tubules (Figs. 10-12).

\section{Discussion:}

The hemoglobin molecule is affected by any alteration in its environment. The absorption spectrum of the $\mathrm{Hb}$ molecule can give some evidence about variations in its conformation (El-Bediwi et al. 2013). The results of this study showed that exposure of $\mathrm{Hb}$ molecules to EMF was induced great changes in its absorption spectrum and these results in agreement with the study of (Hassan and Abdelkawi, 2010) who indicated that exposure of the animals to magnetic fields caused changes in the absorption spectrum of $\mathrm{Hb}$ molecules. The results presented in this study clearly demonstrated that 
exposure of adult male rats to $1.5 \mathrm{mT}, 50 \mathrm{~Hz} \mathrm{EMF}$ for a period of 9 consecutive hours had a significant reduction effect on serum testosterone. This result is in agreement with Yildiz-Gulay et al. (2017) who found that exposure of rabbits to EMF results a decrement in testosterone concentrations. The present results of histological observations showed degenerative changes in the testis exposed to EMF. These findings are consistent with that of Elbaz and ghonimi (2015) who reported that exposure of mature male rats to $50 \mathrm{~Hz}, 0.1 \mathrm{mT}$ Magnetic Field results in severe pathological lesions in the testis. In the present study, MOLE was showed a protective role against induced effects and this is due to Moringa oleifera micronutrients contain antitumor, anti-epileptic, anti-diuretic, anti-inflammatory and venomous bite characters. Moringa oleifera extract (MOE) contains specific plant pigments with demonstrated powerful anti-oxidative ability such as vitamins C, E, A, caffeoylquinic acids, carotenoidslutein, alpha-carotene, and beta carotene, kaempferol, quercetin, rutin (Akunna et al., (2012) and Maida $\boldsymbol{e t}$ $\boldsymbol{a l}$. (2005)). Our results are in agreement with BinMeferij and El-kott, (2015) who indicated that chronic exposure to EMF marked testicular damage which can be decreased by MOLE.

\section{Conclusion:}

This study indicates that exposure to the electromagnetic field may cause conformational changes in hemoglobin molecules and significantly decrease serum testosterone. The results showed also degenerative changes in the testis of male albino rats. However, all these changes were decreased by oral sublimation of Moringa oleifera leaves extract. Therefore it can be concluded that MOLE had a protective role against the EMF induced effects. So one who forced to exposed to EMF can be recommended to take Moringa oleifera leaves extract in his diet by suitable dose defined by the doctor.

\section{References:}

Abd El-Hady, A.M. and El-Tahawy, N.A. (2015): The possible protective effect of vitamin $\mathrm{E}$ and / or silymarin on rat testes exposed to
$950 \mathrm{MHz}$ electromagnetic field. Journal of Bioscience and Applied Research, 1(3): 97111.

Adah, A.S.; Adah, D.I.; Biobaku, K.T. and Adeyemi, A.B. (2018): Effects of Electromagnetic radiations on the male reproductive system. Anatomy Journal of Africa. Vol 7 (1): 1152 - 1161.

Akunna, G.G.; Ogunmodede, O.S.; Saalu, C.L.;Ogunlade, B.;Bello, A.J. and Salawu EO.( 2012): Ameliorative effect of Moringa oleifera (drumstick) leaf extracts on chromium-induced testicular toxicity in rat testes. World J Life. Sci. Med Res, 2: 20.

Azab, A.E.; Khalat, A.M.; Ebrahim, S.A. and Albasha, M.O. (2018): Electromagnetic Fields and Its Harmful Effects on the Male Reproductive System. Bioscience and Bioengineering, 4(1):1-13.

Bahaodini, A.; Owjfard, M.; Tamadon, A. and Jafari S.M. (2015): Low frequency electromagnetic fields long-term exposure effects on testicular histology, sperm quality and testosterone levels of male rats. Asian Pac J Reprod. 4(3): 195-200.

Bin-Meferij, M.M. and El-kott, A.F. (2015): The radioprotective effects of Moringa oleifera against mobile phone electromagnetic radiation-induced infertility in rats. Int $\mathrm{J}$ Clin Exp Med; 8: 12487-97.

Drury, R. A.; Wallington, E.A. and Cameron, S.R. (1973): Carleton's "histological technique", $4^{\text {th }}$ ed., Oxford Univ. Press, New York, Toronto.

Elbaz, A. and Ghonimi, W.A. (2015): Exposure Effects of $50 \mathrm{~Hz}, 1$ Gauss Magnetic Field on the Histoarchitectur changes of Liver, Testis and Kidney of Mature Male Albino Rats. Journal of Cytology \& Histology.6:4

El-Bediwi, A.B.; Saad, M.; El-kott, A.F. and Eid, F. (2013): Influence of electromagnetic radiation produced by mobile phone on some biophysical 
blood properties in rats. Cell Biochem. Okechukwu, P.U.; Okwesili, F.N. and Parker, Biophys. 65(3):297-300.

E.J., (2013): Phytochemical and acute

Hassan, N. S. and Abdelkawi, S.A. (2010): Changes in molecular structure of hemoglobin in exposure to $50 \mathrm{~Hz}$ magnetic fields. Nature and Science, 8 (8): 236-243.

Khalafalla M. M., Abdellatef, E., Dafalla, H. M., Nassrallah, A. A., Aboul-Enein, K. M., Lightfoot, D. A., El-Deeb, F. E., El-Shemy, H. A. (2010): Active principle from Moringa oleifera Lam leaves effective against two leukemias and a hepatocarcinoma. African Journal of Biotechnology, 9 (49): 8467-8471.

Maida, A.; Farooq, A.; Raziya, N.; Umer, R.; Kazi, T. and Nadeem, M. (2005): Mineral Composition of Moringa oleifera leaves and pods from different regions of Punjab, Pakistan. Asian Journal of Plant Sciences. toxicity studies of Moringa oleifera ethanol leaf extract. Int J Life Sci Btand Pharm. 2(2):66-71.

Yildiz-Gulay, O.; Gulay, M. S.; Ata, A. and Balic, A. (2017): Effects of electromagnetic field on testes and semen characteristics in male New Zealand white rabbits. Indian J. Anim. Res., 51 (4): 665-669.

Syarifuddin, N. A.; Toleng, A. L; Rahardja, Ismartoyo and Yusuf, M. (2017):

Improving Libido and Sperm Quality of Bali Bulls by Supplementation of Moringa oleifera Leaves. Media Peternakan 40(2):88-93.

Trivelli, L.A.; Ranney, H. M. and Lai, H. T. (1971): Hemoglobin components in patients with diabetes mellitus. N. Eng. J. Med. 353362. 